\title{
Information Seeking through Students' Eyes: The MIT Photo Diary Study
}

\section{Tracy Gabridge, Millicent Gaskell, and Amy Stout}

In 2006, a team of librarians at MIT conducted a photo diary study of thirty-two students' academic information-seeking behaviors. The aim of this qualitative research approach, based on analyzing a week of student-generated photos and diary entries, was to understand how to design MIT's library systems and services to more effectively support students' information-seeking practices. The project generated data on 275 distinct information-seeking tasks used by the students. Examination of their goals, tasks and methods informed the MIT Libraries' priorities and planning efforts for improving library online systems in the following areas: improving discovery and search, incorporating trusted resources in finding tools and increasing links to library resources in external sites popular with the MIT community.

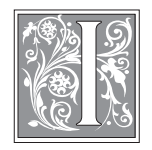

n 2006, a team of librarians at MIT conducted a photo diary study of thirty-two students' academic information-seeking behaviors. The aim of this qualitative research effort, based on analyzing a week of student-generated photos and diary entries, was to understand how we could design our library systems and services to more effectively support students' information-seeking practices. The study was intended to complement the MIT Libraries' fall 2005 quantitative survey of the MIT students, faculty, and research staff that assessed the community's awareness of library services as well as their perceived quality and value. The survey provided extensive quantitative data that could be analyzed and acted upon. But while the survey method painted an accurate picture of the community's library-related practices through one lens, it did not provide detailed insights into the broader context of the daily research life of students.

We were particularly interested in learning whether our library systems and services were experienced by student users as being "seamless" - invisibly enabling their productive and creative activity. By using qualitative research methods, we hoped to elicit themes and trends from student narratives that could inform our efforts to improve library ser-

Tracy Gabridge is Co-Head Librarian, Engineering \& Science Libraries, Massachusetts Institute of Technology; e-mail: tag@mit.edu. Millicent Gaskell is Head Librarian, Dewey Library, Massachusetts Institute of Technology; e-mail: mrg@mit.edu. Amy Stout is Computer Science Librarian, Barker Engineering Library, Massachusetts Institute of Technology; e-mail: astout@mit.edu. 
vices and systems. The specific method we used was to ask students to record their academic information-seeking activities over seven days, including their use of the Internet, consulting books, discussing strategies with classmates, or meeting with faculty. Photographs and notes taken by the students were used to jog their memories as they recounted their activities during follow-up interviews. These accounts gave us a new understanding of where, why, when, and how the students sought information. These insights generated ideas for improving library services by accommodating the ways in which students already conduct their research.

\section{Background}

The information landscape has changed dramatically over the past decade. Google, with its single search box, speedy results display, and relevancy ranking has changed user expectations for all search interfaces. In addition, social networking features such as tagging support more collaborative interaction among Internet users. Search tools and information are tightly integrated in today's electronic environment. For example, a user of Google Scholar may access the citation, abstract, and even full text of a document all from what appears to be one interface, masking the fact that the index, the publication, and the linking software come from three separate providers. Finally, the sheer volume of information available online has grown enormously. These changes in the information environment mean that students are searching for information in different ways than they might have a few years ago.

Research has shown that students expect to find most of their information online. ${ }^{1}$ They tend to turn to the Internet first, especially Google, when embarking upon research. ${ }^{2}$ Today's students are busier than ever, and they highly value the time-saving features of electronic information retrieval. ${ }^{3}$ Today's students, known as Millennials (anyone born be- tween 1976 and 1996), expect to find all the information they need, for work and play, within easy electronic reach. ${ }^{4}$ For them, learning takes place everywhere, thanks to the portability of laptops, cell phones and PDAs. Today's students move associatively through information rather than linearly, having, as one researcher put it, "hyperlinked minds." 5

Traditional information literacy education has the potential to increase the use of library resources, but it has not yet changed the ways in which students approach research as they advance through their college careers. Van Scoyoc and Cason found in 2006 that college juniors and seniors were no less likely to turn to the Internet first for research than firstand second-year students. At the same time, despite evidence that they lack basic information literacy skills, students consistently rate themselves as effective users of information. ${ }^{6}$

To understand how to apply the findings in this study more broadly, it is important to comprehend how MIT students vary in information-use practices from students at other universities. MIT enrolls about 4,000 undergraduates and 6,000 graduate students each year. Of the 4,000 undergraduates, nearly 2,000 are in the school of engineering. Despite common stereotypes, MIT students are more well rounded today than ever before. ${ }^{7}$ Today's techies, the traditional mainstay of MIT's enrollment, are equally attractive to top liberal arts schools and are actively recruited by them. Yet, recent comparative surveys show that MIT students are less likely than their counterparts at other universities to ask for help from librarians, are less likely to have found an interesting book through browsing at the library, and are less likely to use the library for group study and discussion. They are similar to their peers at other institutions in having used special collections in their work, and the extent to which they use computers in requesting materials from libraries. ${ }^{8}$

Given the rapidly changing information landscape and a desire to fundamen- 
tally examine how library systems need to evolve, MIT librarians wanted to find out more about what their own students were doing. MIT librarians designed a study inspired by the methodology used by Foster and Gibbons at the University of Rochester. In the Rochester study, students were given cameras to document their study habits. The photos the students took were later used in the course of interviews to help the students remember what they had done during a period of time. The open-ended, qualitative approach taken by the Rochester group provided data relevant to particular questions of the researchers in addition to suggesting entirely new questions and avenues for future research. One of the librarians described the process as a way to "discover the unexpected." 9 This sort of ethnographic research is useful for challenging assumptions held by an organization and informing plans for large-scale or long-term changes in systems. ${ }^{10}$

\section{How the MIT Photo Diary Study was conducted \\ Methodology}

The Photo Diary Study used a methodology from the field of anthropology known as a "cultural probe." The premise behind a cultural probe is that better results can be achieved by studying people in their own environment. Since it is not possible to observe participants at all times, a device such as a camera or a notebook is used by participants to help them record what they do and is later used to prompt memory of the events captured. This method is currently used in the field of information architecture to get a more complete picture of users and their culture. ${ }^{11}$ As a qualitative approach, a cultural probe tends to generate creative thinking and insight related to a user group's behavior rather than statistically significant data results. Nevertheless, results can be coded and analyzed to suggest trends and to move beyond impressions and anecdotes, bringing a larger pattern of behavior into sharper focus.
In this case, we believed the cultural probe would help spark new insights into the information needs of our users by allowing us to see more of the breadth of their information-seeking behavior. The 2005 MIT Libraries' quantitative survey was sent to nearly 14,000 individualsand almost half responded, including over 50 percent of the student body and 30 percent of the faculty. The answers to the more than 50 questions, including two open-ended comment boxes, provided a rich amount of data concerning the communities' opinions of the quality and value of the MIT Libraries' resources and services. However, the survey could not provide details about how and whether these resources and services were being used. We anticipated that seeing this complete context would help highlight the service gaps that the MIT Libraries needed to fill.

Students took pictures, captured screen shots, and recorded notes of what steps they followed every time they looked for information related to their academic life over the course of a specific week. They were then asked to bring the photos, screen shots, and notes to an interview and to use those images and words to jog their memories about the details of what they did. The undergraduates participated during the spring semester. The graduate student portion of the study occurred between semesters, which likely caused an underreporting of courserelated goals and tasks. Each student received a \$50 Amazon gift certificate in exchange for their time. Because we were interviewing students for this project, we secured permission and training from MIT's Committee on the Use of Humans as Experimental Subjects (COUHES).

For this study, we had hoped to recruit a manageable pool of 20 graduate students and 20 undergraduate students, with participation in proportion to the enrollment in the five schools at MIT. Despite the best efforts of the study team, only 16 graduate students and 16 undergraduates were found to par- 


\begin{tabular}{|l|c|c|}
\hline \multicolumn{3}{|c|}{$\begin{array}{c}\text { TABLE 1 } \\
\text { Volunteers }\end{array}$} \\
\hline \hline \multicolumn{1}{|c|}{ School } & $\begin{array}{c}\text { \# of Graduate } \\
\text { Students }\end{array}$ & $\begin{array}{c}\text { \# of Undergraduate } \\
\text { Students }\end{array}$ \\
\hline Art and Architecture & 1 & 0 \\
\hline Engineering & 7 & 7 \\
\hline Science & 3 & 3 \\
\hline $\begin{array}{l}\text { Humanities, Arts } \\
\text { and Social Sciences }\end{array}$ & 3 & 2 \\
\hline $\begin{array}{l}\text { Sloan School of } \\
\text { Management }\end{array}$ & 2 & 1 \\
\hline Undecided & NA & 3 \\
\hline Total & 16 & 16 \\
\hline
\end{tabular}

\section{Analysis}

The interviewing teams' notes were first analyzed to identify and summarize major trends and issues. Next, interviewers created cards for each student information-related task documented or described by the students, and each card was annotated to identify the broader goal of that task and all methods used in completing the task. The interviewers then did a card sort to

ticipate; and, while participation was not proportional to enrollment, we did have student participants from each of MIT's five schools. We recruited from a pool of volunteers who had indicated their willingness to give feedback for future projects in the 2005 Library Survey. The focus of the study was solely on students, as they form the largest group of users of the MIT Libraries, and also because the time-intensive nature of the study made faculty participation unlikely.

\section{Interviews}

The interviews consisted of a list of questions, including a few warm-up and closing questions, with most of the time spent on having each student tell the story of his or her week, showing photos, screen shots, and any notes prepared for the student's diary. The interviewing teams for this project consisted of eight librarians, working in four teams of two people each. At every interview, one librarian asked questions while the other took notes. Both librarians reviewed the notes after the interview was completed. These notes represented a best effort by each of the interviewing teams, but no effort was made to create an actual transcript of the interview. This sometimes limited the ability of the researchers to check back with original data when questions came up later. group cards describing identical goals. From these groupings, goal categories were created. For example, the goal category "course-related preparation" included individual goals of studying for an exam, completing a homework assignment, and doing course readings. The process was repeated for tasks and methods to create relevant categories for each set. Lists of information-seeking goals, tasks, and methods were created from the cards. The cards were coded with demographic data for each student participant, including their school, department, years at MIT, and age. The coded data from the cards were collated, standardized, and entered into a database from which quantitative information-seeking patterns were extracted. More than 500 methods were employed for 275 tasks and goals in the study sample.

\section{What We Learned from the MIT Photo Diary Study}

One of the goals of the Photo Diary Study was to determine the range of information activities of students at MIT. We broke our analysis into six major categories: goals, tasks, methods, success, efficiencies, and trusted resources. While we give a summary here, the complete report of our findings can be found at http://hdl.handle. net/1721.1/33456. 


\begin{tabular}{|c|c|}
\hline \multicolumn{2}{|c|}{$\begin{array}{l}\text { TABLE } 2 \\
\text { Questions }\end{array}$} \\
\hline \multirow[t]{6}{*}{ Warm-up Questions } & What department are you in? \\
\hline & How long have you been at MIT? \\
\hline & Would you mind telling us your age? \\
\hline & $\begin{array}{l}\text { \# of times a month you use the physical } \\
\text { MIT Libraries? }\end{array}$ \\
\hline & $\begin{array}{l}\text { \# of times a month you use the electronic } \\
\text { resources of the MIT Libraries? }\end{array}$ \\
\hline & $\begin{array}{l}\text { \# of times a month you search for } \\
\text { information not using the MIT Libraries? }\end{array}$ \\
\hline \multirow{10}{*}{$\begin{array}{l}\text { Interview Questions } \\
\text { (used to flesh out details as needed) }\end{array}$} & What were you looking for? \\
\hline & Where were you doing your research? \\
\hline & When were you doing your research? \\
\hline & What research strategies did you use? \\
\hline & What sources did you use? \\
\hline & How did you learn about these sources? \\
\hline & What devices did you use? \\
\hline & What worked? \\
\hline & What problems did you have? \\
\hline & How often do you do this task? \\
\hline \multirow[t]{3}{*}{ Closing Questions } & $\begin{array}{l}\text { Are their any other tasks that you typically } \\
\text { do that you didn't do this week? }\end{array}$ \\
\hline & Do you ever do programming or scripting? \\
\hline & $\begin{array}{l}\text { Have you ever used RSS, social } \\
\text { bookmarking tools, or Firefox extensions? }\end{array}$ \\
\hline
\end{tabular}

\section{Goals of Student Information-seeking Activities}

For every task performed by the students, the study team identified the goal of the task. A summary of the students' goals, broken down by graduate and undergraduate, provides a picture of the general differences between the goals pursued by these two groups.

As we expected, due to the fact that the graduate student portion of the study was conducted during a semester break, graduate students were more focused on their research, while undergraduate work was defined by classroom assignments. While it would have been advantageous to have a snapshot of graduate student work during a semester when they com- bine their research work with class work, the graduate students generally take fewer classes per semester than undergraduates and typically are involved in research endeavors from the beginning of their degree program. With this study, we obtained a great deal of data about their research work but not how they approach course work.

Despite the difference in timing of the study for the two populations, there was variation between the number of goal categories pursued by graduate students (11 categories) and undergraduates (8 categories). Undergraduates, unlike their graduate counterparts, tended to seek information in support of social activities when not doing work for a class. Graduate 


\begin{tabular}{|l|c|}
\hline \multicolumn{1}{|c|}{ TABLE 3} \\
$\begin{array}{c}\text { Purposes of Students' Information-Seeking } \\
\text { Tasks: Goal Categories }\end{array}$ \\
\hline \hline \multicolumn{1}{|c|}{ Top 3 Goal Categories for Graduate Students } \\
\hline \multicolumn{2}{|c|}{$\%$ of Total Tasks } \\
\hline $\begin{array}{l}\text { Research (thesis or research } \\
\text { assistantship) }\end{array}$ & $64 \%$ \\
\hline $\begin{array}{l}\text { Prepare for presentations or } \\
\text { publications }\end{array}$ & $14 \%$ \\
\hline Current awareness & $9 \%$ \\
\hline \multicolumn{2}{|c|}{ Top 3 Goal Categories for Undergraduate Students } \\
\hline Course-related preparation & $75 \%$ \\
\hline $\begin{array}{l}\text { Research (undergraduate } \\
\text { research programs/projects) }\end{array}$ & $7 \%$ \\
\hline Current awareness & $7 \%$ \\
\hline
\end{tabular}

top ten categories accounted for 87 percent of all tasks.

While many of the tasks did not require resources from the MIT Libraries (for instance, attending lectures, taking notes, and organizing information), the top four task categories had high potential for requiring resources that are usually supplied by libraries.

Some differences in tasks between graduates and undergraduates were apparent. Undergraduates frequently studied course materials or sought information to complete a course assignment. Also, they were more likely to search for factual information or conduct quick information lookups (say, for definitions, students concentrated on information related to personal development, networking, and writing computer code when they weren't working on their research.

\section{Tasks Students Performed}

Research subjects engaged in a variety of information-seeking tasks over the course of one week. Interviewers elicited 23 categories from the interview notes. The equations, or images). Graduate students spent more time organizing their notes or managing their bibliographic citations in an effort to synthesize new information with their ongoing work.

Interviewers found that undergraduates spent less time than graduate students on any individual information-seeking task. Undergraduates tended to juggle many assignments for many courses

\section{TABLE 4}

Task Categories From Student Interviews

\begin{tabular}{|l|c|c|c|}
\hline \hline Task Category & $\begin{array}{c}\text { \# of Tasks } \\
\text { Graduate } \\
\text { Students }\end{array}$ & $\begin{array}{c}\text { \# of Tasks } \\
\text { Undergraduate } \\
\text { Students }\end{array}$ & Totals \\
\hline Search for a known item & 21 & 25 & 46 \\
\hline Search for information on a topic & 20 & 21 & 41 \\
\hline Find facts or do a quick lookup & 7 & 28 & 35 \\
\hline Search for a partially-known item & 13 & 20 & 33 \\
\hline Take notes and organize information & 13 & 3 & 16 \\
\hline Complete a class assignment & 0 & 16 & 16 \\
\hline $\begin{array}{l}\text { Check web sites/RSS/scripts/email for current } \\
\text { awareness }\end{array}$ & 9 & 6 & 15 \\
\hline Study for class & 0 & 15 & 15 \\
\hline Learn about a software program & 9 & 4 & 13 \\
\hline Do course readings & 0 & 10 & 10 \\
\hline
\end{tabular}


simultaneously. Graduate students were involved in longer-term research efforts with deadlines in the far future. Consequently, the nature of the undergraduates' tasks was less complex. Undergraduates' tasks were frequently satisfied with information that was quickly available or "good enough." Graduate students typically couldn't settle for "good enough" information and had to search further and deeper for reliable information.

\section{Methods Used to Accomplish Tasks}

Interviewers recorded the methods used by students for each information-seeking goal and task. Students used a variety of creative methods to perform their tasks and accomplish their goals. Often they employed more than one method to complete a task, either due to multistep processes or unsatisfactory results. As part of the analysis, interviewers noted which methods were used to begin each task. As a result, a number of dominant first-choice methods emerged indicating method preferences.

Of the methods analyzed, 32 percent involved a library-provided resource or service. Graduate students averaged 1.90 methods per task, while undergraduates averaged 1.78 methods per task.

Table 5 shows the top methods used to accomplish a task in the study and the number of times that method was used first.

The students relied on Web-based tools such as Google (Search, Print, Images, or Scholar), Amazon, and Wikipedia for many of their information needs. Thirty-nine percent of all tasks in the study involved one or more of these methods. Students also relied on a valued network of colleagues that included peers, other students, lab cohorts, as well as faculty. Eighteen percent of all tasks included a consultation with a person in the student's personal network.

Table 6 highlights the most frequently used method of each of the four top tasks.

\begin{tabular}{|l|c|c|}
\hline \multicolumn{3}{|c|}{ TABLE 5 } \\
Methods Used to Accomplish Tasks \\
\hline \hline Method Category & $\begin{array}{c}\text { Total } \\
\text { Occurrences }\end{array}$ & $\begin{array}{c}\text { \# of Times Used } \\
\text { First on a Task }\end{array}$ \\
\hline Search Google & 78 & 50 \\
\hline Go directly to a known URL not otherwise specified & 60 & 38 \\
\hline Use the library catalog to browse or search & 30 & 17 \\
\hline Search licensed citation databases & 26 & 8 \\
\hline Use course web sites & 23 & 14 \\
\hline Review notes/handouts taken in class/lab & 17 & 9 \\
\hline Search e-resources finding tool & 16 & 11 \\
\hline Read textbook & 13 & 3 \\
\hline Consult other students & 13 & 7 \\
\hline Consult with guest lecturer/ faculty & 12 & 8 \\
\hline Search Google Scholar & 12 & 5 \\
\hline Search licensed full-text databases & 10 & 5 \\
\hline Physically browse a collection & 9 & 6 \\
\hline Refer to books in personal library & 9 & 6 \\
\hline Retrieve a print resource from a library & 9 & 4 \\
\hline Use Wikipedia & 9 & 4 \\
\hline
\end{tabular}




\begin{tabular}{|l|l|c|}
\hline \multicolumn{3}{|c|}{ TABLE 6 } \\
\hline Most Frequently Used Methods for the Top Four Tasks \\
\hline \hline Task & \multicolumn{1}{|c|}{ Method } & $\begin{array}{c}\text { No. of } \\
\text { Occurrences }\end{array}$ \\
\hline Find facts or do a quick lookup & Search Google & 25 \\
\hline Search for a partially-known item & Search Google & 18 \\
\hline Search for information on a topic & Search a citation database & 17 \\
\hline Search for a known item & Search the library catalog & 16 \\
\hline
\end{tabular}

Searching Google was the most frequently used method for finding facts and searching for a partially known item. Searching the MIT Libraries' catalog was the most frequently used method for known-item searching. For finding information on an unknown topic, searching citation databases narrowly edged out Google as the most frequently used method, though searching Google was the method most frequently used first. Upon further analysis, the data showed that when Google was used as a first method, it was necessary 58 percent of the time to use at least one additional method to satisfy the requirements of the task.

\section{Success, Efficiency, and Trusted Sources}

For each task, the study team recorded three additional sets of metrics: 1) how successful the student judged him/herself to be at completing the task; 2) how efficient the interviewer(s) felt the student had been at accomplishing the task; and 3) if the student used a "trusted resource." We defined a trusted resource as a person, source, or tool that the student had used previously or that had been recommended to them by someone they trusted. For the first metric, there were several occasions in the study in which the student felt that s/he had been successful at a task, but the interviewers did not agree with that assessment. A rating of "efficient" did not take into account whether the interviewer felt that the student had found an excellent source of information. In a few cases the students were successful and efficient, but the piece of information they found was less than optimal. Such an outcome is one limitation of this measurement. The trusted resource metric was developed once the interviewers realized how often students relied on particular resources or persons to the exclusion of others, even when they did not necessarily have confidence that the resource would yield a successful outcome. In one example of the use of a trusted resource, the student used PubMed as a starting point for finding articles not related to medical topics,

\begin{tabular}{|c|c|c|}
\hline \multicolumn{3}{|c|}{$\begin{array}{c}\text { TABLE } 7 \\
\text { Assessment of Success, Efficiency and Use of Trusted Sources in } \\
\text { Information-seeking Tasks }\end{array}$} \\
\hline & $\begin{array}{l}\text { Graduate } \\
\text { Students }\end{array}$ & $\begin{array}{c}\text { Undergraduate } \\
\text { Students }\end{array}$ \\
\hline & Yes & Yes \\
\hline $\begin{array}{l}\text { Did the student judge him or herself successful at } \\
\text { completing his/her task? }\end{array}$ & $86 \%$ & $93 \%$ \\
\hline $\begin{array}{l}\text { In the opinion of the interviewer, was the student } \\
\text { efficient at accomplishing his/her task? }\end{array}$ & $77 \%$ & $85 \%$ \\
\hline $\begin{array}{l}\text { Did the student use a trusted person or tool in } \\
\text { accomplishing his/her task? }\end{array}$ & $80 \%$ & $69 \%$ \\
\hline
\end{tabular}




\begin{tabular}{|c|c|c|c|c|c|c|}
\hline \multicolumn{7}{|c|}{$\begin{array}{c}\text { TABLE } 8 \\
\text { Top Four Task Categories And Success/Efficiency/Trusted Source Metrics } \\
\text { Sorted By Student Status }\end{array}$} \\
\hline & \multicolumn{3}{|c|}{ Graduate students } & \multicolumn{3}{|c|}{ Undergraduate students } \\
\hline Task Category & Successful & Efficient & $\begin{array}{l}\text { Used } \\
\text { Trusted } \\
\text { Source }\end{array}$ & Successful & Efficient & $\begin{array}{l}\text { Used } \\
\text { Trusted } \\
\text { Source }\end{array}$ \\
\hline Search for a known item & $86 \%$ & $86 \%$ & $76 \%$ & $84 \%$ & $84 \%$ & $64 \%$ \\
\hline $\begin{array}{l}\text { Search for information } \\
\text { on a topic }\end{array}$ & $80 \%$ & $40 \%$ & $90 \%$ & $82 \%$ & $64 \%$ & $57 \%$ \\
\hline $\begin{array}{l}\text { Search for a partially- } \\
\text { known item }\end{array}$ & $62 \%$ & $69 \%$ & $92 \%$ & $95 \%$ & $75 \%$ & $80 \%$ \\
\hline $\begin{array}{l}\text { Find facts or do a quick } \\
\text { lookup }\end{array}$ & $100 \%$ & $100 \%$ & $86 \%$ & $96 \%$ & $86 \%$ & $86 \%$ \\
\hline
\end{tabular}

simply because she had previously had success with it when performing research in a different subject area. We gleaned a key fact from each of the three metrics we recorded: students considered themselves to be overwhelmingly successful; interviewers found the students to be relatively efficient; and students often chose to use a trusted resource.

Table 7 summarizes the overall results for these metrics.

The success, efficiency, and trusted resource metrics were applied to the top four task categories as demonstrated in table 8 .

Overall, the graduate students were more likely than the undergraduate students to use a trusted resource in accomplishing their information-related tasks, though both relied heavily on trusted resources. It is possible that the difference arose because of differences in the nature of the work done by the two groups. Many graduate students work in a lab or research group and thus had colleagues working on the same or similar research areas with whom they could consult. Undergraduates, however, are new to their field of study and were often experimenting with new resources for information. Anecdotally, many students verbalized that they had automatically gone to certain resources because they had used them before or because someone they trusted had recommended them. Trust in online resources is built from frequent use as documented in a recent OCLC study. ${ }^{12}$ Word-of-mouth influences on service selection and trust is also a well-documented phenomenon in the social sciences. ${ }^{13}$

For tasks like topical searching or searching for partially known items, graduate students were, by their own admission, less successful and, by our analysis, less efficient. However, the graduate students were consistently involved in more complex research where discovering much-needed data may be difficult or nearly impossible. For undergraduate students searching for information on a topic, there were a notably smaller percentage of tasks for which they relied on trusted resources, and yet they remained quite efficient in their pursuits. It is possible that this result is due to the less complex nature of their inquiries as compared to the graduate students.

With respect to products and services provided by the MIT Libraries, students mentioned a variety of resources. The students frequently recalled how and when they learned about specific tools. Many students learned about the resources via personal recommendations from faculty or other students. A small number discovered resources by a number of methods, such as browsing the MIT Libraries' database of electronic resources, 
browsing physical collections, or talking to a librarian.

\section{Next Steps Based on Findings of MIT Photo Diary Study}

Hearing the students' narratives was instrumental in forming ideas about priorities and plans for improving the MIT Libraries' online systems for search and discovery of information resources. The findings of the study confirmed trends about which we had suspicions, but the findings also surprised us into thinking in new ways about how students find information sources. The study prompted the identification of four broad categories for action:

- Make discovery and search easier and more effective

- Incorporate trusted resources in finding tools

- Continue to put links to the MIT Libraries where the users are

- Implications for other MIT Libraries services

\section{Make Discovery and Search Easier and More Effective}

While the students engaged in knownitem searching and topical searching in roughly equal proportions, topical searching was more difficult and timeconsuming for students than known-item searching. The graduate students typically sought significant detail on a topic, whereas the undergraduates looked for general overviews. When confronted by the vast array of tools available to them, the students often exhibited uncertainty about what to do next and frequently reverted to tools with which they were familiar instead of digging deeper to understand how new tools could be more effective. The students instinctively used a variety of discovery tools not available to them through traditional library interfaces, such as "customers who bought this also bought" links or "browse similar titles" links found in tools like Amazon. com. Improving topical searching could be facilitated in a variety of ways:
1. Reduce the number of starting points for discovery; allow users to search many tools at once. Because no single tool will allow for searching all library resources at once, the MIT Libraries are planning to reduce the number of places a user must go to in a search for information. One interface could search the metadata and content that is owned by the MIT Libraries via a metadata aggregator tool, such as those offered commercially by Endeca or Siderean, to combine the catalog, the institutional repository, the MIT Libraries' Web pages, a visual images database, etc. The second interface could be a careful deployment of a federated search tool to allow for search of a limited number of licensed resources by broadcast search methods.

2. Provide more guidance in the selection of tools to use for discovery. The MIT Libraries' current e-resources finding tool, Vera (http://libraries.mit.edu/vera) provides only a subject-categorized, alphabetical list of resources with descriptions. In the study, the students found this level of information about the resources inadequate for making informed decisions about which databases to try, so they often didn't try any of them and relied on tools with which they were familiar (such as PubMed for finding article citations not medically related). With the implementation of a federated search tool, more clues to aid in evaluating resources will be crucial. Pregrouping of core resources for cross-database searching is one expected advance in this area.

3. Provide user-friendly access to metadata in results sets for further search strategy refinement and discovery. Students in the study favored tools that provided smart links to related information and narrowing categories. There is extensive metadata that is hidden away in full record screens within catalogs that could serve that function. Faceted browsing interfaces serve to make the metadata accessible in a highly useful way and will be a likely direction for our future interfaces. 


\section{Incorporate Trusted Resources in Finding Tools}

A surprising finding of the study was the extent to which the students relied on the opinions of others when choosing tools and information to use. Whether they sought input from others, either in person or online, the students used others' opinions to make decisions about what resources to use. The team knew that students relied on familiar tools, but the pervasiveness of this preference moved this issue to the forefront of our thinking in a way that it hadn't been before. It is important for libraries to incorporate this essential social phenomenon into our tools and systems. Incorporation of trusted resource data into library tools may happen in several ways:

1. Add links within library tools. Students would find tools useful that created links among library resources such as the online catalog, citation databases, and trusted nonlibrary sources such as Amazon, book review sites, and Google Print. By including these links, the MIT Libraries can facilitate students' easy and efficient movement into and out of library resources, greatly reducing the duplicate searches they must perform now to get from one resource to another.

2. Incorporate social networking, reviewing, and similar user input capabilities into library tools. Several students wished they could have access to the opinions of their peers and faculty about which resources are good to use. User tagging of resources and allowing for local review and commenting about resources within the MIT Libraries would be of value in the education of MIT students. Student feedback indicated that it would not be necessary to have a particular faculty or student name attached to a comment, knowing their role would provide enough context (for instance, a notation such as "a faculty member from Mechanical Engineering").

3. Expose MIT Libraries' circulation and use data to help people understand what is heavily used. Knowing how much a resource is used would help our users understand how important a resource is within the topic searched. The utility of the results would be increased in a tool such as a metadata aggregator, if it were possible to offer sorting of results based on use, or to incorporate use data into relevancy/ranking algorithms. Use data to be incorporated could include circulation data for items in the catalog, journal use data from electronic resource management tools or publishers, and download metrics from other local digital tools. Circulation data could also power a "people who borrowed this book also borrowed..." feature that would help expose the "long tail"14 of resources that is a particular strength of libraries.

4. Incorporate relevancy rankings into results lists of library tools. Students in the study expected results to be ranked by relevancy in general, and they also expected the relevancy algorithms to be excellent at identifying the most appropriate resources first. Based on these results, the MIT Libraries will have relevancyranked results in the tools we implement in the future.

\section{Continue to Put Links to the MIT Libraries Where the Users are}

While students began only 23 percent of all tasks in the study by using library resources, they ended up consulting a resource from the MIT Libraries in about 36 percent of their tasks. Since students often started their information seeking outside the MIT Libraries' Web space, it would make sense to continue to find ways to embed links, tools, and MIT Libraries' metadata into widely popular Web sites, search engines, and databases to lead our community back to resources available to them in the MIT Libraries. There are a variety of ways to continue this work:

1. Continue to partner with outside Web sites. The MIT Libraries have already shared holdings data with Google Scholar and Windows Live Academic to provide our users with deep linking to library resources. We should continue to be open to partnerships of this nature. 
2. Take advantage of browser extensions and toolbars that enable integration of library links on sites often used by students. For example, Firefox plug-ins enable direct links from a title on Amazon to a title in our catalog. Extensions like these make it possible to incorporate and integrate our services and links without needing the cooperation of the outside Web site. These are becoming more popular as users in the outside world are finding useful ways to link libraries, bookstores, and other Web sites and services. For example, the MIT Libraries now offer the LibX toolbar and a Greasemonkey script that automates lookup in the MIT Libraries catalog.

3. Support the development of tools like browser extensions and toolbars within the MIT community. In a technology-oriented student community like MIT, we need to invite our students to modify and improve library tools. In the study, we learned that a small but significant number of students were interested in manipulating library data themselves, and many knew a fellow student who they believed would be interested in doing this. It would take only a few students contributing their own ideas to begin to create novel and productive tools. The MIT Libraries have begun to welcome such contributions by creating an "MIT Libraries Betas" page (http://libraries.mit.edu/betas/) where we are placing tools that aren't quite ready for full-production mode or those that have been contributed by others. The first student-contributed beta was a coursepicking application written by computer science students and based on MIT Libraries' "Simile" research into integrating heterogeneous metadata. The betas site has been highlighted periodically on the MIT Libraries' homepage.

4. Migrate traditional library finding tools, such as the catalog, to platforms that enable Web services. In their current configuration, the library management system and the electronic resources management (ERM) system hosted by the MIT Libraries are largely inflexible because it is difficult to create applications that access the data contained within them. We would like our platforms to enable easy sharing of data with other applications by third parties who see new uses for it. For instance, if all MIT Libraries' metadata for owned content contained within existing systems were available in a metadata aggregator tool that had Web services enabled, we could allow others to create applications using that data.

\section{Implications for Other MIT Libraries Services}

While the photo diary study provided a significant amount of information to support decision-making for the evolution of online tools, it inevitably also offered direct support for other types of actions and services that would enhance the information-seeking experiences of the MIT students. As in the case of the Rochester study, these insights were an unexpected benefit of the qualitative method we had used, and the study team agreed that it was important to share these findings within the library system. Most notably:

1. Raise awareness: The Photo Diary Study echoed the results from the 2005 MIT Libraries Survey in that it showed that students are often unaware of the vast array of relevant and helpful information and tools available to them from the MIT Libraries.

2. Reduce barriers to services: Because ease and speed of access are highly valued by MIT students, we recommended a review of services to identify and address the barriers students experience in their use of libraries services.

3. Focus on customer service: MIT students prefer to discover things on their own and not to ask for help, except from trusted peers. It is critical that every interaction with the MIT Libraries be positive in order to overcome this barrier as well as to allow the MIT Libraries to become part of the students' networks of trusted resources.

4. Close the skills gap: The undergraduates interviewed in this study did not demonstrate the level of informationseeking skills needed to carry them successfully into graduate school. Continued 
efforts should be directed to assisting current graduate students with getting up to speed, as well as preparing undergraduates for future academic careers.

5. Assist with personal information management: The number of tasks and the amount of time the graduate students devoted to information management were significant. Continued promotion and instruction on bibliographic management tools like Endnote, RefWorks, and Zotero will help students increase their productivity and provide an opportunity for the MIT Libraries to partner with the students in additional ways.

\section{Conclusion}

Since the completion of the Photo Diary Study, the MIT Libraries have moved forward on several of the recommendations outlined here. Project SimpLR (http://libstaff.mit.edu/simp/) has charged two task forces: one to implement a metasearch tool and the other to investigate acquiring or building a metadata aggregator tool, such as WorldCat Local. The MIT Libraries' Betas page was implemented in the summer of 2006.

The MIT Libraries are one institution among many that are working to rapidly develop systems-based solutions that will radically improve information discovery for their users. From North Carolina State's innovative catalog interface using Endeca software, to University of Rochester's eXtensible catalog effort, and many others, big changes are underway. The MIT Libraries hope both to contribute to this progress and to take advantage of innovations begun by others. We believe strongly that by staying focused on the needs and information-seeking practices of our students, we will be able to create a sustained level of improvement in our systems that will contribute to their ultimate success in their academic lives.

\section{Notes}

1. Anna M. Van Scoyoc and Caroline Cason, "The Electronic Academic Library: Undergraduate Research Behavior in a Library without Books," portal: Libraries and the Academy 6 (2006): 47-59; Lesley M. Moyo, "Electronic Libraries and the Emergence of New Service Paradigms," Electronic Library 22 (2004): 220-30.

2. Van Scoyoc and Cason, "The Electronic Academic Library"; Christen Thompson, "Information Illiterate or Lazy: How College Students Use the Web for Research," portal: Libraries and the Academy 3 (2003): 259-68; Joan K. Lippincott, "Next Generation Students and Libraries," EDUCAUSE Review (2005), available online at http://library.case.edu/ksl/admin/slc/workingdocuments/net_generation_students.pdf [Accessed 30 October 2007].

3. Studying Students: The Undergraduate Research Project at the University of Rochester, ed. Nancy Fried Foster and Susan Gibbons (Chicago: Association of College and Research Libraries, 2007); Lippincott, "Next Generation Students and Libraries."

4. Van Scoyoc and Cason, "The Electronic Academic Library"; Moyo, "Electronic Libraries and the Emergence of New Service Paradigms."

5. Foster and Gibbons, Studying Students.

6. Van Scoyoc and Cason, "The Electronic Academic Library"; Foster and Gibbons, Studying Students; Thompson, "Information Illiterate or Lazy."

7. Marilee Jones, "New Kids on the Block: Observations on the Newest Generation of MIT Students," MIT Faculty Newsletter 14 (2001): 12-15.

8. Institutional Research, Office of the Provost, MIT. CSEQ Report. C. Robert Pace and George D. Kuh, College Student Experiences Questionnaire Research Program (Indiana University Center for Postsecondary Research and Planning, 5th ed., 2001).

9. Foster and Gibbons, Studying Students.

10. Catherine Courage and Kathy Baxter, Understanding Your Users: A Practical Guide to User Requirements Methods, Tools, and Techniques (San Francisco: Morgan Kaufman, 2004).

11. Hugh Beyer and Karen Holtzblatt, Contextual Design (San Diego: Academic Press, 1998); Courage and Baxter, Understanding Your Users.

12. OCLC, Sharing, Privacy and Trust in Our Networked World: A Report to the OCLC Membership (2007). Available online at www.oclc.org/reports/pdfs/sharing.pdf. [Accessed 24 October 2007].

13. Chip Walker, "Word of Mouth," American Demographics 17 (1995): 38-45.

14. Chris Anderson, "The Long Tail," Wired 12 (2005): 170-77. 
Providing aceêss to the world's vojeê since $19 \%$

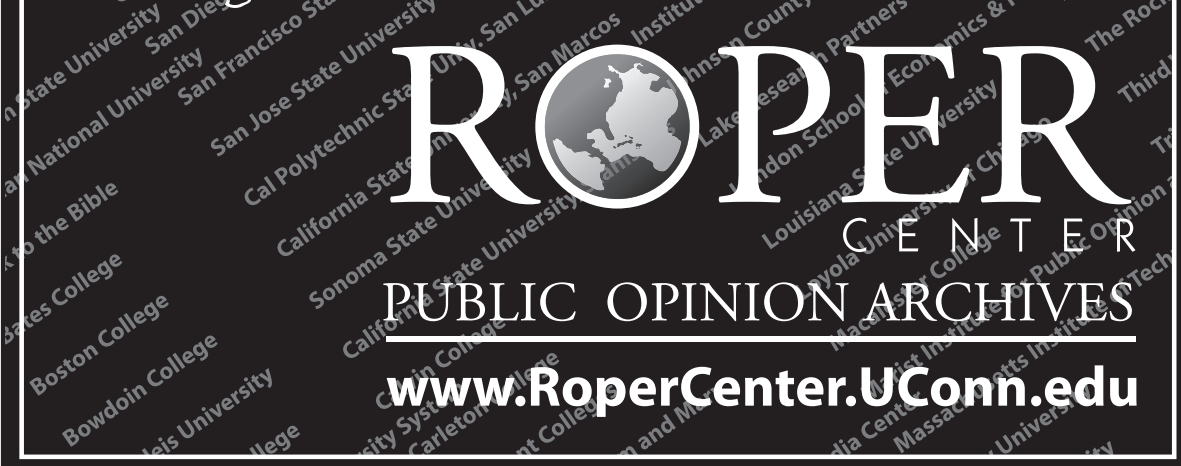

